

\section{Sumário}

I. Crônicas do Direito Internacional ...............................................1

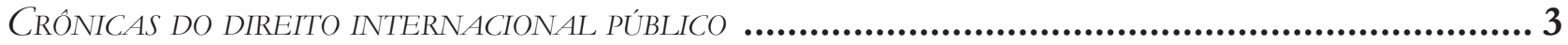

A resolução 2272 (2016) do Conselho de Segurança das Nações Unidas - O POSICIONAMENTO DA ONU FACE ÀS ALEGAÇÕES DE ABUSO E EXPLORAÇÃo SEXUAL POR SUAS

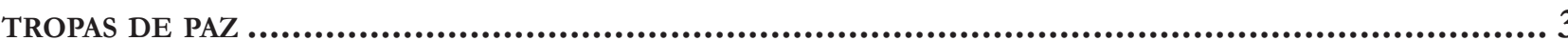

Sarah Dayanna Lacerda Martins Lima

CRÓNICAS DE DiREITo INTERNACIONAL PRIVADO...................................................................

Nadia de Araujo, Marcelo De Nardi, Gustavo Ribeiro, Fabrício Polido e Inez Lopes

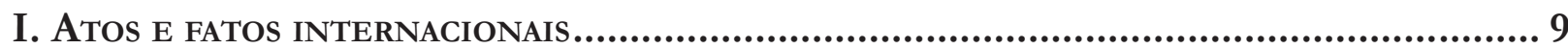

Crônica 1. Novidades de 2017 SObRE CIRCulaÇÃo faCilitada DE SENTENÇAS ESTRANGEIRAS 9

Crônica 2: O Direito Transnacional e os episódios das Carnes.........................................16

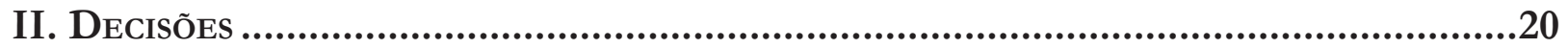

Crônica 3: A Irresistível ForÇa da ORDEM PÚblica E A HOMOLOGaÇÃo DE SENTENÇAS

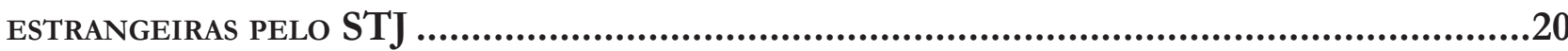

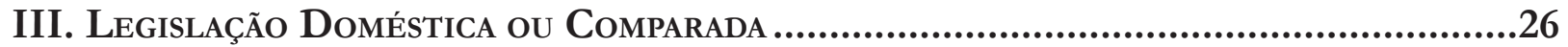

Crônica 4 - Dignidade da pessoa humana e mudança de paradigma da Lei de Migração

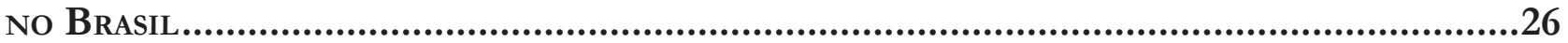

II. Dossiê especial: Direito Internacional dos InVEstimentos ................35

Non-adjudicatory State-State Mechanisms in Investment Dispute Prevention and Dispute Settlement: Joint Interpretations, Filters and Focal Points 
Mapping the Duties of Private Companies in International Investment Law .50 Nitish Monebhurrun

LA LÉGALITÉ DE L'INVESTISSEMENT DEVANT L'ARBITRE INTERNATIONAL: À LA RECHERCHE D'UN POINT D'ÉQUILIBRE .73 Hervé Ascensio

Host STATES AND STATE-STATE INVESTMENT ARBITRATION: STRATEGIES AND CHALlENGES......81 Murilo Otávio Lubamdo de Melo

Right to Regulate, Margin of Appreciation and Proportionality: Current Status in Investment Arbitration in Light of Philip Morris V. Uruguay. .95 Giovanni Zarra

Investments on Disputed Territory: Indispensable Parties and Indispensable Issues....122 Peter Tzeng

The Influence of General Exceptions on the Interpretation of National

Treatment in INTERNATIONAL INVESTMENT LAW. 140 Louis-Marie Chauvel

UMA PRoposta de REFleXão SObRe os ACFIs: Até QUE PONTO O TRATAMENTo de NAÇão MAIS FAVORECIDA PODE MINAR A ESTRATÉGIA POLÍTICA QUE OS EMBASA? 160

Michelle Ratton Sanchez Badin, Daniel Tavela Luis e Mario Alfredo de Oliveira

ECUADOR's 2017 TERMINATION OF TREATIES: HOW NOT TO EXIT THE INTERNATIONAL INVESTMENT REGIME 179

Jose Gustavo Prieto Muñoz

ONE BELT, ONE ROAD: NOVAS INTERFACES ENTRE O COMÉRCIO E OS INVESTIMENTOS INTERNACIONAIS 193

Flávio Marcelo Rodrigues Bruno e Marilda Rosado de Sá Ribeiro

III. Artigos Sobre outros TEMAS..................................................... 214

TolerânCIA E REFugIO: UM ENSAIO A PARTIR Do ACORdo EU-TurQUiA 216 Flávia Cristina Piovesan e Ana Carolina Lopes Olsen 
O TRATAMENTO do APÁtridA NA NOVA LEI DE MIGRAÇÃo: ENTRE AVANÇOS E RETROCESSOS...237 Jahyr-Philippe Bichara

O caráter humanista da Lei de Migrações: aVAnços da Lei N. 13.445/2017 E Os desafios DA REGULAMENTAÇÃO. 254 Marcelo Dias Varella, Clarice G. Oliveira, Mariana S.C. Oliveira e Adriana P. Ligiero

Reform of the United Nations Security Council: The Emperor Has No Clothes.268 Ljubo Runjic

A IDEIA DE QUe os LATINO-AMERICANOS PREFEREM O AUTORITARISMO À DEMOCRACIA À luz da reinterpretação dos Critérios do Programa das Nações Unidas para o DesenVolvimento 286

Gina Marcilio Pompeu e Ana Araújo Ximenes Teixeira

A PRoteção da ORIENTAÇÃo SEXUAL E IDENTIDAdE DE GÊNERO DIVERSAS NA CORTE PENAL internacional: Entre Realpolitiks E Os Direitos Humanos

Gustavo Bussmann Ferreira

A desnacionalização e as violações de direitos humanos na República Dominicana. 331 Daniela Menengoti Gonçalves Ribeiro e Rodrigo Ichikawa Claro Silva

CompetênCia do TPI no Caso do ATAque ao hospital de Kunduz: uma análise ENVOLVENDO A JURISDiÇÃo do TPI EM RELAÇÃO A NACIONAIS DE EsTAdOS NÃO-PARTE do Estatuto DE Roma

Filipe Augusto Silva e Renata Mantovani de Lima

A CRIMINALIZAÇÃo DOS IMIGRANTES EM SITUAÇÃo IRREGULAR NA ITÁliA: BIOPOLÍtica E DIREITO PENAL DO AUTOR.

Maiquel Angelo Dezordi Wermuth e Jeannine Tonetto de Aguiar

The New Rules On Trade And Environment Linkage In Preferential Trade Agreements

Alberto do Amaral Júnior e Alebe Linhares Mesquita

Beyond THE Border between the North and the South: towards a Decolonization of EPISTEMOLOGIES AND FIELDS OF RESEARCH ON MERCOSUR 
A aplicabilidade da Convenção de Montreal no direito brasileiro.

Aziz Tuffi Saliba e Alexandre Rodrigues de Souza

REgIME DE TRANSPARÊNCIA FISCAL NA TRIBUTAÇÃo DOS LUCROS AUFERIDOS NO EXTERIOR (CFC RULES): LACUNAS E CONFLITOS NO DIREITO BRASILEIRO

Paulo Rosenblatt e Rodrigo Torres Pimenta Cabral

As Regras Brasileiras de Tributação de Controladas e Coligadas no Exterior: verdadeiras Controlled Foreign Company (CFC) Rules? .......................................465

Melina de Souza Rocha Lukic e Amanda Almeida Muniz

O RETORNO DE BENS CULTURAIS

Aziz Saliba e Alice Lopes Fabris

Direitos culturais e Nações Unidas: uma análise a partir da Declaração Sobre a eliminação de Todas as Formas de Intolerância e Discriminação Baseadas na Religião OU NA CRENÇA

Leilane Serratine Grubba e Márcio Ricardo Staffen

OS REFLEXOS DA PROTEÇÃO INTERNACIONAL DA PROPRIEDADE INTELECTUAL PARA O DESENVOLVIMENTO INTERNO: UMA ANÁLISE SOBRE O SISTEMA PATENTÁRIO BRASILEIRO E A TRANSFERÊNCIA DE TECNOLOGIA

Michele M. Segala e Isabel Christine S. De Gregori

O CASO HIPOTÉTICO DA MORTE DO EMBAIXADOR FRANCÊS NA ESPANHA: DUAS ESPÉCIES DE IUS gentium em Francisco de Vitoria

Rafael Zelesco Barretto

De volta À BeVilaqua: anÁlise ECONÔMICA dA APLICAÇão do ART. $9^{\circ}$ DA LINDB Às OBRIGAÇÕES CIVIS CONTRATUAIS

Danielle Cristina Lanius e Ivo Teixeira Gico Jr 


\title{
Os reflexos da proteção internacional da propriedade intelectual para o desenvolvimento interno: uma análise sobre o sistema patentário brasileiro e a transferência de tecnologia*
}

\author{
The effects of the international protection \\ of the intellectual property for inside \\ development: an analysis of the Brazilian \\ patent system and the technology transfer
}

Michele M. Segala**

Isabel Christine S. De Gregori***

\section{Resumo}

A pesquisa se propôs ao estudo sobre a proteção internacional da Propriedade Intelectual, buscando averiguar em que medida ela impacta no desenvolvimento interno, sobretudo no sistema patentário brasileiro. Para tanto, o trabalho foi dividido em dois momentos, destinando-se o primeiro à realização de um apanhado evolutivo sobre os instrumentos internacionais de proteção, quais sejam a Convenção de Paris e o Acordo TRIPS, compreendendo a problemática envolvendo a transferência de tecnologia. No segundo momento, dedicou-se à análise do sistema patentário brasileiro enquanto propulsor do desenvolvimento interno. Utilizando-se do método de abordagem dedutivo e do método e procedimento histórico, acompanhados da pesquisa bibliográfica e documental, foi possível observar que o sistema internacional de proteção trouxe fortes reflexos para o desenvolvimento interno em virtude das decisões políticas adotadas pelo Brasil, ao aderir ao Acordo TRIPS sem estar efetivamente preparado para isso.

* Recebido em 20/06/2017

Aprovado em 10/07/2017

** Mestranda no Programa de Pós Graduação em Direito da Universidade Federal de Santa Maria. Bolsista pela Coordenação de Aperfeiçoamento de Pessoal de Ensino Superior (CAPES). Pesquisadora no Grupo de Pesquisa Propriedade Intelectual na Sociedade Contemporânea, certificado pelo CNPQ. Email:mi.segala00@gmail.com

*** Doutora em Desenvolvimento Regional. Professora do Curso de Direito e do Programa de Pós-Graduação em Direito da UFSM. Líder do Grupo de Pesquisa Propriedade Intelectual na Sociedade Contemporânea, certificado pelo CNPQ. E-mail: isabelscdg@gmail.com
Palavras-chave: Propriedade Intelectual. proteção internacional. Desenvolvimento interno. sistema patentário.

\section{Abstract}

The research one proposed to study about international protection of Intellectual Property, searching to investigate how it impacts on the inside development, especially in the Brazilian patent system. Therefore, the work was divided into two stages, one designating the first to realization of a evolutionary bunched about international instruments of protection, which are the Paris Convention and the TRIPS Agreement, understanding the problematic about technology transfer. In the second moment, one dedicated to analysis about Brazilian patent system as a propelling of the inside 
development. One using the deductive method and of the historical method, as well as bibliographical and documentary research, it was possible to observe that the international protection system brought strong effects for the inside development due to political decisions adopted by Brazil, to adhere to Agreement TRIPS without being effectively prepared for this.

KeyWords: Intellectual property. International protection. Inside development. Patent system.

\section{INTRODUÇÃo}

Os estudos sobre a Propriedade Intelectual vêm adquirindo importância crescente nas últimas décadas. Seja com relação aos Direitos Autorais, ou à Propriedade Industrial, são inumeráveis as questões que têm gerado debate e até mesmo questionamento, como a proteção de softwares e o domínio público, no primeiro caso, ou quanto às particularidades envolvendo as modalidades de propriedade industrial, especialmente quando relacionadas ao Desenvolvimento.

Independentemente do enfoque que se pretenda dar à pesquisa, o estudo sobre o Sistema Internacional de Proteção da Propriedade Intelectual sempre se faz presente, por ser fundante da própria ordem interna que disciplina a matéria. Foi a partir dos instrumentos normativos internacionais que se convencionou os parâmetros mínimos a serem adotados na construção do ordenamento jurídico interno, além de trazerem formas de gerenciamento e transferência de tecnologia entre países. A maneira como o Sistema Internacional foi consolidado gera intensos debates, sobretudo no que diz respeito à transferência de tecnologia de países desenvolvidos para os menos desenvolvidos. A rigidez das previsões internacionais teria impactado especialmente no sistema patentário dos países com um grau inferior de desenvolvimento, tornando-os reféns do monopólio exercidos pelas grandes corporações e multinacionais.

Diante dessa perspectiva, o presente trabalho tem por escopo traçar uma reflexão justamente sobre os impactos da proteção internacional da Propriedade Intelectual no desenvolvimento interno, buscando abordar essa problemática envolvendo a transferência de tecnologia, bem como averiguar como resta sedimentado o sistema patentário brasileiro e de que maneira isso pode influenciar no grau de desenvolvimento interno do país.
Para tanto, adota-se o método de abordagem dedutivo, uma vez que a reflexão parte da análise das normatizações existentes, tanto em nível internacional como interno, para investigar mais a fundo os seus reflexos para o desenvolvimento nacional. Não obstante, utiliza-se do método de procedimento histórico, uma vez que se faz um panorama geral não apenas da evolução normativa em âmbito internacional, mas também das condições em que os instrumentos foram sendo firmados. Como técnica de pesquisa, adota-se a pesquisa bibliográfica e a análise documental, com enfoque para instrumentos como a Convenção de Paris e o Acordo TRIPS.

\section{A PROTEÇÃO INTERNACIONAL DA PROPRIEDADE INTELECTUAL E A PROBLEMÁTICA ENVOLVENDO A TRANSFERÊNCIA DE TECNOLOGIA ENTRE PAÍSES DESENVOLVIDOS E EM DESENVOLVIMENTO}

As criações advindas do intelecto humano tendem a ganhar o mundo assim que saem do campo das ideias e passam a se materializar. Por esse motivo, demandam um enfrentamento não apenas na ordem jurídica interna, mas também em âmbito global. É nesse cenário que a tutela da Propriedade Intelectual ganha importância, desempenhando, conforme ressalta Marinho ${ }^{1}$, um importante papel na construção dos pilares do direito internacional, já que os direitos por ela tutelados necessitam de uma abrangência para além das fronteiras.

Esse "reconhecimento da importância da proteção internacional traz consigo a necessidade de celebração de convenções internacionais capazes de coordenar as leis internas dos Estados" ". Mas a construção do Sistema Internacional de proteção da Propriedade Intelectual se deu a passos lentos, considerada a dificuldade de se encontrar um consenso entre as pretensões dos países envolvidos. Com efeito, o contraste entre as configurações dos países desenvolvidos em relação aos que ainda se encontravam em estágio de desenvolvimento dava ensejo a fortes embates no decorrer das tratativas internacionais.

1 VARELLA, Marcelo Dias; PLATIAU, Ana Flávia Barros; SCHLEICHER, Rafael T. Desenvolvimento Tecnológico, Pesquisa Pública e Propriedade Intelectual: Análise da Miríade de Normas Internacionais. In: Propriedade Intelectual e Desenvolvimento. Marcelo Dias Varella (Org.). São Paulo: Lex, 2005, p. 306.

2 BASSO, Maristela. O Direito Internacional da Propriedade Intelectual. Porto Alegre: Livraria do Advogado, 2000, p. 22. 
Após realizar um estudo sobre o contexto internacional da Propriedade Intelectual, Varella ${ }^{3}$ identifica a existência de três distintas modalidades de países, classificação esta que adota a produção de tecnologia e o interesse pelos direitos de propriedade intelectual como critérios comparativos. De acordo com as suas observações, na primeira modalidade estariam os tecnologicamente excluídos, que são importadores de tecnologia e detentores de muito poucas, ou até mesmo nenhuma patente de invenção, representando a maior parte dos países. A segunda modalidade seria composta por alguns países desenvolvidos e regiões de países em desenvolvimento, sendo conhecidos como adaptadores de tecnologia. Já no terceiro grupo estariam alguns poucos países que dominam a produção mundial de tecnologia e de patentes, como é o caso dos Estados Unidos, da Alemanha, do Japão, do Reino Unido, dentre outros. Estes, sozinhos, recebem cerca de $93 \%$ de todos os benefícios econômicos advindos do sistema de propriedade intelectual.

Essa classificação está intimamente relacionada ao nível de desenvolvimento de cada país e até mesmo aos diferentes índices observados em distintas regiões de um mesmo país. Conforme bem observa Correa, "países diferentes são afetados diferentemente pelos direitos de propriedade intelectual." "Tal premissa se mostra fundamental na compreensão sobre a maneira como a proteção internacional da propriedade intelectual impactou de forma mais ou menos favorável em cada Estado nação, assim como as influências exercidas por cada Estado na consolidação desse sistema protetivo.O trabalho de harmonização legislativa entre os diversos países teve início com as Uniões de Paris e de Berna, em 1883 e 1884, respectivamente, sendo mais tarde revigorado pela Organização Mundial da Propriedade Intelectual - OMPI, em 1967 e finalmente consolidado pelo Acordo TRIPS, em 1994. ${ }^{5}$

Enquanto a Convenção de Paris veio regular o ramo da Propriedade Industrial, a Convenção de Berna passou a disciplinar os Direitos de Autor. Nas palavras de Maristela Basso, graças à essas duas Convenções, "estabeleceu-se o princípio da proteção mínima, aceito pelos Estados Unionistas, abaixo do qual nenhuma legislação poderia ficar. [...] O que as Uniões de Paris e de Berna

3 VARELLA, Marcelo Dias. Propriedade Intelectual e Desenvolvimento. São Paulo: Lex, 2005, p. 03

4 Ibidem., p. 50.

5 BASSO, Maristela. Op. Cit., p. 22. não conseguiram ficou a cargo da OMPI e tem sido revigorado pelo TRIPS.”

No que tange à proteção específica da Propriedade Industrial, a Convenção de Paris foi o primeiro tratado de cunho universal a cuidar do tema, tendo o Brasil como um dos primeiros a ratifica-lo, ao lado de alguns países desenvolvidos. Desde então, setores foram sendo incluídos ou excluídos da proteção conforme o interesse estratégico de cada país. ${ }^{7}$

Ainda sobre a Convenção de Paris, esclarece Barbo$\mathrm{sa}^{8}$ que quando a mesma foi negociada houve a prevalência do entendimento no sentido de que não caberia a padronização das normas substantivas, relativas a marcas e patentes nas várias legislações nacionais, optando-se por estabelecer um mecanismo de compatibilização entre as normas, permitindo a diversidade nacional.

A previsão quanto à desnecessária padronização de normas representou um ponto extremamente favorável para a adesão dos mais variados países do mundo, que poderiam resguardar sua soberania interna para disciplinar a matéria da maneira que melhor lhes aprouvesse. $\mathrm{O}$ Brasil aderiu à Convenção de Paris em 1992, por meio do Decreto n ${ }^{\circ} 635$. $^{9}$

Essa prerrogativa, contudo, foi deixada de lado quando do firmamento do Acordo TRIPS. Conforme observa Denis Barbosa ${ }^{10}$, "O ambiente depois do TRIPS não é mais o da Convenção de Paris, com seu respeito à diversidade nacional". Essa primeira consideração sobre o acordo revela uma da tensões que marcaram a sua celebração.A tensão que antecedeu o firmamento do acordo TRIPS teve início em meados de 1986, quando, por insistência dos Estados Unidos e de mais alguns países desenvolvidos, as discussões sobre os direitos de propriedade intelectual foram levados para serem tratados no Gatt - Acordo Geral de Tarifas e Comércio, oportunidade em que o tema foi vinculado ao comércio internacional. Durante a última rodada de tratativas, que

6 VARELLA, Marcelo Dias. Op. Cit., p. 177.

7 VARELLA, Marcelo Dias. Propriedade Intelectual e Desenvolvimento. São Paulo: Lex, 2005, p. 177.

8 BARBOSA, Denis Borges. Trips e a Experiência Brasileira. In: Propriedade Intelectual e Desenvolvimento. Marcelo Dias Varella (Org.). São Paulo: Lex, 2005. Pp. 135.

9 BRASIL. Presidência da República. Decreto no 635, de 21 de agosto de 1992. Promulga a Convenção de Paris para a Proteção da Propriedade Industrial, revista em Estocolmo a 14 de julho de 1967. Disponível em: < http://www.planalto.gov.br/ccivil_03/decreto/1990-1994/D0635.htm> Acesso em: 20 mar. 2017.

10 BARBOSA, Denis Borges. Op. Cit., p. 168. 
ocorreu Uruguai, se encerrando em 1994 com a criação da OMC - Organização Mundial do Comércio, foi criado um anexo ao acordo constitutivo dessa organização, que veio a ser conhecido como TRIPS - Acordo Relacionado aos Direitos de Propriedade Intelectual ${ }^{11}$

A consolidação da Organização Mundial do Comércio foi impulsionada pela aceleração do movimento de globalização e pela intensificação do comércio internacional e o interesse dos países desenvolvidos em salvaguardar suas indústrias e comércio. ${ }^{12}$ Em virtude disso, considerando que o Acordo TRIPS foi criado no seio da OMC, inequívoca se mostra a sua atenção voltada para o comércio internacional, o que justifica a conversão dos bens intelectuais em verdadeiras mercadorias. Conforme esclarece Benett ${ }^{13}$, com o propósito de sustentar a observância das normas e assegurar a fluidez do comércio entre os Estados-membros, a OMC criou um sistema de solução de controvérsias, onde qualquer Estado membro pode encaminhar seu conflito à OMC quando se verificar que foram infringidos os direitos decorrentes dos acordos.

Esse foi um dos aspectos mais relevantes para que os assuntos envolvendo direitos da propriedade intelectual fossem introduzidos na OMC. Com efeito, diante da instituição desse sistema de resolução de controvérsias tornou-se possível controlar a efetiva implementação desses direitos bem como das demais diretrizes trazidas pelo Acordo TRIPS no ordenamento interno dos países-membros.O Acordo TRIPS, desde as suas tratativas iniciais, foi alvo de fortes críticas, as quais ainda se fazem presentes no momento atual. O Brasil foi um dos principais atores negociadores durante as discussões internacionais da rodada Uruguai do Gatt. Liderando os países do terceiro mundo, o Brasil se posicionou contra a formação de um quadro rígido de normas sobre propriedade intelectual. ${ }^{14}$

11 BENETTT, Daniela Vanila Nakalski. Proteção Às Patentes de Medicamentos e Comércio Internacional. In: Propriedade Intelectual e Desenvolvimento. Welber Barral e Luiz Otávio Pimentel (Orgs.). Florianópolis: Fundação Boiteux, 2006, p. 343-344.

12 GRANGEIRO, Alexandre; TEIXEIRA, Paulo Roberto. Repercussões do Acordo de Propriedade Intelectual no acesso a medicamentos. In: Propriedade Intelectual: tensões entre o capital e a sociedade. VILLARES, Fábio (Org.) São Paulo: Paz e Terra, 2007, p. 115.

13 BENETTI, Daniela Vanila Nakalski. Proteção Às Patentes de Medicamentos e Comércio Internacional. In: Propriedade Intelectual e Desenvolvimento. Welber Barral e Luiz Otávio Pimentel (Orgs.). Florianópolis: Fundação Boiteux, 2006. Pp. 345.

14 VARELLA, Marcelo Dias; PLATIAU, Ana Flávia Barros;
Os Estados Unidos, por sua vez, pressionavam o país internamente, para a adoção de uma norma ampla e nos fóruns internacionais. Chegou-se inclusive a impor sanções comerciais contra o Brasil, em 1988, de aproximadamente 1,8 bilhões de dólares em 1995, caso a lei não fosse finalmente aprovada no Congresso $\mathrm{Na}$ cional. ${ }^{15}$

Sobre esse mesmo aspecto, destaca Roland ${ }^{16}$, que foi a partir do marco da Eco 92, ocorrida no Rio de Janeiro, que a pressão americana para que o Brasil viesse a se filiar ao sistema multilateral de regulamentação da propriedade intelectual se intensificou, vindo a ser finalmente consubstanciada no Acordo TRIPS. Tal fato, ainda de acordo com o autor, revela o caráter eminentemente estratégico dos mecanismos de apropriação e privatização do conhecimento, que são tidos como promotores do desenvolvimento e da hegemonia econômica.Dentre as principais características do Acordo TRIPS está a extensão da obrigatoriedade da concessão de direitos sobre Propriedade Intelectual para praticamente todos os campos do conhecimento. ${ }^{17}$ Com efeito, o acordo prevê um conjunto mínimo de setores para os quais é obrigatório ter direitos de propriedade intelectual. Logo, ao ratificá-lo, os países foram obrigados a criar normas internas no mesmo sentido, o que proporcionou um efeito de universalização das convenções internacionais, que até então eram ratificadas por alguns poucos países desenvolvidos apenas. ${ }^{18}$

A inserção da Propriedade Intelectual, em sentido amplo, na Ordem Econômica global, por meio do Acordo TRIPS, colocou em evidência uma questão fundamental, que diz respeito à transferência de tecnologia.

SCHLEICHER, Rafael T. Desenvolvimento Tecnológico, Pesquisa Pública e Propriedade Intelectual: Análise da Miríade de Normas Internacionais. In: Propriedade Intelectual e Desenvolvimento. Marcelo Dias Varella (Org.). São Paulo: Lex, 2005, p. 338.

15 Ibidem.

16 ROLAND, Manoela Carneiro. O debate sobre o Desenvolvimento sob a perspectiva estratégica da Propriedade Intelectual e da sua regulamentação internacional. In: Patrícia Aurélia Del Nero (Coord.) Propriedade Intelectual e Transferência de Tecnologia. Belo Horizonte: Fórum, 2011, p. 42.

17 GRANGEIRO, Alexandre; TEIXEIRA, Paulo Roberto. Repercussões do Acordo de Propriedade Intelectual no acesso a medicamentos. In: Propriedade Intelectual: tensões entre o capital e a sociedade. VILLARES, Fábio (Org.) São Paulo: Paz e Terra, 2007, pp. 116.

18 VARELLA, Marcelo Dias. Políticas Públicas para Propriedade Intelectual no Brasil. In: Propriedade Intelectual e Desenvolvimento. Marcelo Dias Varella (Org.). São Paulo: Lex, 2005, p. 178. 
Para Fontes ${ }^{19}$, o estudo sobre a transferência de tecnologia deve partir de um ângulo intervencionista, "dado o seu caráter de promotora do desenvolvimento econômico e parâmetro regulador da transmissão da boa técnica e da propriedade intelectual."

Mas antes de se compreender a transferência, imprescindível se mostra a compreensão sobre o conceito de tecnologia. Nesse sentido, de acordo com as explicações de Assafim ${ }^{20}$, adotando-se uma concepção ampla, pode-se definir a tecnologia como o conjunto de conhecimentos científicos cuja adequada utilização pode ser fonte de utilidade ou de benefícios para a Humanidade. Por outro lado, de maneira mais restrita, pode-se conceituar a tecnologia como o conjunto de conhecimentos e informações próprio de uma obra, que pode ser utilizado de forma sistemática para o desenho, desenvolvimento e fabricação de produtos ou a prestação de serviços.Já quando se remete à transferência da tecnologia, segundo Corrêa ${ }^{21}$, adotando-se um sentido amplo, é possível compreendê-la como um negócio jurídico pelo qual uma das partes obriga-se a transmitir determinados conhecimentos aplicáveis a um processo produtivo, sendo remunerada pela outra parte. Contudo, adverte o autor que, para que haja real transferência de tecnologia é fundamental a assimilação dos conhecimentos pelo receptor.Ademais, o artigo sétimo do Acordo TRIPS, que trata dos objetivos a serem buscados por meio do mesmo, assim refere:

A proteção e a aplicação de normas de proteção dos
direitos de propriedade intelectual devem contribuir
para a promoção da inovação tecnológica e para a
transferência e difusão de tecnologia, em benefício
mútuo de produtores e usuários de conhecimento
tecnológico e de uma forma conducente ao bem-
estar social econômico e a um equilíbrio entre
direitos e obrigações. ${ }^{22}$

Como se depreende, o Acordo em questão elencou expressamente dentre os seus objetivos a transferência e a difusão de tecnologia, o que deve ser perseguido sem

19 FONTES, André R. C. Perfis de Transferência de Tecnologia. In: Propriedade Intelectual e Transferência de Tecnologia. Patrícia Aurélia Del Nero (Org.) Belo Horizonte: Fórum, 2011.

20 ASSAFIM, João Marcelo de Lima. A Transferência de Tecnologia no Brasil (aspectos conceituais e concorrenciais da Propriedade Industrial). Rio de Janeiro: Lumen Juris, 2013, p. 14.

21 CORRÊA, Daniel Rocha. Contratos de Transferência de Tecnologia. Belo Horizonte: Movimento editorial da Faculdade de Direito da UFMG, 2005, p. 96.

22 BRASIL. Presidência da República. Decreto nº 1.355 , de 30 de dezembro de 1994. Disponível em: < http://www.planalto.gov.br/ ccivil_03/decreto/antigos/d1355.htm> Acesso em: 20 mai. 2017. que se deixe de lado a finalidade maior do bem estar social econômico. Contudo, há quem entenda que os objetivos declarados no bojo do Acordo TRIPS “serviram apenas de ferramenta hipócrita de negociação, tendo sido absolutamente negligenciados."23

Um tema bastante pertinente e que também se insere nesse debate diz respeito à questão do acesso a medicamentos e o desenvolvimento interno em termos de saúde e bem-estar da população nacional. Problemática que sempre se mostrou transparente diz respeito à dificuldade de acesso à saúde considerados os altos custos dos medicamentos, cujas fórmulas são patenteadas por potentes multinacionais que monopolizam os proventos do conhecimento fármaco-científico.

Atentando para esse problema, que traz consequências negativas para a grande maioria dos países no campo global, é que se buscou uma flexibilização do Acordo TRIPS. Foi por meio da Declaração de Doha, firmada em novembro de 2001, que o combate a epidemias e doenças que afetam os países pobres foi tornado uma preocupação global, a partir do que se previu a possibilidade da concessão de licenciamentos compulsórios, para casos de emergência ou urgência nacional. ${ }^{24}$

Prevendo as dificuldades enfrentadas pelos países que se encontram em um estágio de desenvolvimento ainda precoce, a Declaração de Doha reforçou o compromisso de os países desenvolvidos oferecerem incentivos às suas empresas e instituições, com o propósito de promover a transferência de tecnologia para os países menos desenvolvidos. Ainda, previu uma série de flexibilizações a serem aplicadas ao Acordo TRIPS, como a prevalência da liberdade de cada membro para conceder licenças compulsórias, determinando as razões pelas quais elas serão concedidas, bem como as hipóteses que considera como sendo de emergência ou urgência nacional.

Tais flexibilizações repercutem incisivamente na transferência de tecnologia, na medida em que, diante da premissa básica sobre a qual se ancora a ideia de transferência, qual seja, a assimilação pelo receptor, o

23 SILVA, Tatianna Mello Pereira da. Acordo TRIPS: one-sizefits-all? In: Revista de Direito Internacional, v. 10, n. 1, Brasília, 2013, p. 68. Disponível em: < file:///C:/Users/Note\%20Michele/ Downloads/1987-11447-1-PB.pdf> Acesso em: 03 jul. 2017.

24 MERCER, Henrique da Silva. Patente de Medicamentos conforme o TRIPS: O caso da Gripe Aviária. In: Propriedade Intelectual e Desenvolvimento. Welber Barral e Luiz Otávio Pimentel (Orgs.). Florianópolis: Fundação Boiteux, 2006, p. 363 
instrumento da licença compulsória muitas vezes não se mostra suficiente. Isso ocorre quando o país não detém capacidade tecnológica para desenvolver por conta própria aquele objeto que sofreu a quebra da patente. Refletindo sobre essa problemática, Suguieda ${ }^{25}$ esclarece que, para se tratar de transferência de tecnologia, é fundamental que haja capacitação tecnológica nacional. Com efeito, por meio da Declaração de Doha, houve o reconhecimento formal de que os membros da OMC com nenhuma ou insuficiente capacitação no setor farmacêutico poderiam enfrentar dificuldades para fazer uso efetivo do licenciamento compulsório nos termos do Acordo TRIPS. Para o autor, essa dificuldade antecede qualquer problema de segurança jurídica do instituto legal da licença compulsória ou decorrente das regras dos mercados imperfeitos que porventura possam impedir ou limitar a participação de terceiros.Como bem observa Rocha ${ }^{26}$, não restam dúvidas "de que a transferência de tecnologia gera desenvolvimento econômico para o país receptor, mesmo que esse desenvolvimento refira-se apenas ao lucro gerado pelo aumento ou melhora na produção." Contudo, é preciso examinar novas abordagens para a transferência de tecnologia dos países ricos para os pobres, já que esta foi apontada por muitos tratados e declarações internacionais como um dos objetivos do sistema internacional. Falta, ao longo do processo, um maio acompanhamento operacional. ${ }^{27}$

Ademais, é preciso um esforço local de cada país, no delineamento de estratégias que se voltem para os problemas e para as potencialidades de desenvolvimento local.

A partir dessa perspectiva, se passará a analisar a maneira como o Brasil optou por estruturar internamente os Direitos de Propriedade Intelectual, atentando-se para o Sistema Patentário vigente e a maneira como isso impacta no seu nível de desenvolvimento.

25 SUGUIEDA, Márcio Heidi. O Tênue Equilíbrio da Propriedade Intelectual no Brasil. In: Propriedade Intelectual e Transferência de Tecnologia. Patrícia Aurélia Del Nero (Coord.). Belo Horizonte: Fórum, 2011, p. 68-69

26 CORRÊA, Daniel Rocha. Contratos de Transferência de Tecnologia. Belo Horizonte: Movimento editorial da Faculdade de Direito da UFMG, 2005, p. 161.

27 SACHS, Jeffrey. O divisor global de Inovação. In: Propriedade Intelectual e Desenvolvimento. Marcelo Dias Varella (Org.). São Paulo: Lex, 2005, p. 32-33.

\section{RefLeXões SOBRE O DESENVOLVIMENTO INTERNO A PARTIR DO SISTEMA PATENTÁRIO BRASILEIRO}

Partindo de uma análise classificatória dos países integrantes da ordem mundial no que tange ao seu nível de desenvolvimento e dedicando maior atenção à realidade desenvolvimentista do Brasil, é possível identificar o destaque que ele representa no investimento em determinados setores, como o da biotecnologia. Essa observação é feita por Varella, que ainda atenta para o caráter tímido da atuação do Brasil, na medida em que produz menos de $2 \%$ das inovações mundiais:

O Brasil tem capacidade para adaptar tecnologias e reproduzi-las a custos mais baixos no território nacional. Especialmente para esse grupo de poucos países a propriedade intelectual tem uma função muito importante. Ela vai limitar ou estimular o ritmo de desenvolvimento tecnológico do país, em função de políticas favoráveis e diferenciadas em favor de setores estratégicos da indústria nacional, para que se consiga alavancar esse desenvolvimento. $^{28}$

Como se depreende, o Brasil se enquadra no grupo dos países adaptadores de tecnologias. Enquanto dotado da capacidade de adaptar tecnologias já existentes, pode ter um futuro ainda mais promissor no que tange ao seu nível de desenvolvimento econômico caso saiba se utilizar das ferramentas disponibilizadas pela Propriedade Intelectual.

Analisando uma pesquisa realizada por Varella, é possível verificar que a produção de tecnologia se concentra nos países do Norte, resultando na priorização da ciência e tecnologia entre os principais investimentos públicos e privados nesses países. A título ilustrativo, o autor compara o Brasil aos Estados Unidos, referindo que, enquanto estes investiam no final do século passado uma média de $2,8 \%$ do PIB em pesquisa científica, o Brasil investia $0,8 \%$ apenas. $^{29}$

Nesse mesmo sentido, evidencia Albuquerque ${ }^{30}$ que o Brasil faz parte de um conjunto de países que não possuem um sistema de inovação completo (ou madu-

28 VARELLA, Marcelo Dias. Propriedade Intelectual e Desenvolvimento. São Paulo: Lex, 2005, p. 04.

29 Ibidem, p. 173.

30 ALBUQUERQUE, Eduardo da Motta e. Propriedade Intelectual e estratégias para o desenvolvimento. In: Propriedade Intelectual: tensões entre o capital e a sociedade. VILLARES, Fábio (Org.) São Paulo: Paz e Terra, 2007, p. 142. 
ro), da mesma forma que a Índia, a África do Sul e o México, sendo de extrema urgência que comece a investir decididamente na construção desse sistema.

Essa realidade enfrentada pelo Brasil está intimamente relacionada à forma como aderiu ao acordo TRIPS. Sobre esse aspecto, revela Denis Barbosa ${ }^{31}$ que "o legislador brasileiro acabou cedendo à pressão unilateral americana, sem aproveitar-se dos ganhos de razoabilidade que vieram com o TRIPS." Analisando os dispositivos previstos no acordo, mais precisamente, contemplando as suas disposições transitórias, é possível observar que restou resguardada a prerrogativa aos países em desenvolvimento de postergar a vigência do acordo pelo prazo de quatro anos ${ }^{32}$, tendo o Brasil optado deliberadamente por não fazê-lo.

Com efeito, a "padronização das legislações nacionais decorrentes da adesão ao tratado TRIPS deixa de levar em conta as diferenças relevantes entre países em via de desenvolvimento (PVD) e os países de desenvolvimento avançado." 33 Enquanto alguns países tenham se preocupado em aproveitar o período transitório concedido pelo acordo para fortalecer-se internamente, o Brasil prontamente procedeu à uniformização da sua legislação nacional.

Em razão disso, infere-se que os impactos do Acordo TRIPS no Brasil refletem "não o equilíbrio, mas a prevalência irrefreada da tese do predomínio dos interesses dos proprietários, mesmo a despeito do mercado e do comércio", desencadeando o recrudescimento radical do sistema de propriedade. ${ }^{34}$

Conforme pontua Varella ${ }^{35}$, os direitos de propriedade intelectual foram associados ao estímulo da ino-

31 BARBOSA, Denis Borges. Trips e a Experiência Brasileira. In: Propriedade Intelectual e Desenvolvimento. Marcelo Dias Varella (Org.). São Paulo: Lex, 2005, p. 152.

32 BRASIL. Presidência da República. Decreto nº 1.355, de 30 de dezembro de 1994. Disponível em: < http://www.planalto.gov.br/ ccivil_03/decreto/antigos/d1355.htm> Acesso em: 20 mai. 2017.

33 GONTIJO, Cícero. As transformações do sistema de Patentes, da Convenção de Paris ao Acordo Trips. A posição brasileira. Fundação Heinrich Böll. 2005. Disponível em: < http:// paje.fe.usp.br/ $\sim$ mbarbosa/dpi/gontijo1.pdf $>$ Acesso em: 20 mar. 2017, p. 12.

34 BARBOSA, Denis Borges. Trips e a Experiência Brasileira. In: Propriedade Intelectual e Desenvolvimento. Marcelo Dias Varella (Org.). São Paulo: Lex, 2005, p. 148-149.

35 VARELLA, Marcelo Dias. Políticas Públicas para Propriedade Intelectual BARBOSA, Denis Borges. Trips e a Experiência Brasileira. In: Propriedade Intelectual e Desenvolvimento. Marcelo Dias Varella (Org.). São Paulo: Lex, 2005, p. 148-149.Ibidem, p. 178. vação tecnológica, sendo que, com a intensificação do processo de globalização, ganham importância ainda mais estratégica. Partindo desse enfoque, a atribuição de direitos de propriedade intelectual pode significar o estímulo à inovação tecnológica da indústria local, como pode significar também apenas o aumento do domínio do mercado nacional por uma empresa estrangeira.

Ao refletir sobre o modelo padronizado de proteção da Propriedade Intelectual, em artigo publicado na Revista de Direito Internacional, Silva ${ }^{36}$ atenta para o fato de que a Propriedade Intelectual consiste em um dos meios para a consecução de um fim a ser levado em consideração dentro de uma estratégia maior de promoção do desenvolvimento econômico e do bem-estar social mundial.

Nesse sentido, a Propriedade Intelectual pode ser adotada como uma importante ferramenta para a promoção do desenvolvimento interno. Contudo, cada Estado nacional deve "saber quando reforçar ou não os direitos de propriedade intelectual sobre determinados setores, resguardando seus interesses", sob pena de ficar refém das grandes multinacionais. ${ }^{37}$

Embora o Brasil invista pouco, está entre os países em desenvolvimento que mais investe em ciência e tecnologia. O fato de ser dotado de capacidade para adaptar tecnologia de acordo com os recursos que possui em seu próprio território demonstra um certo otimismo para se pensar em uma estratégia que promova de maneira mais efetiva o seu desenvolvimento interno. ${ }^{38}$

Ocorre que, ao aderir ao Acordo TRIPS de maneira automática, sem se valer do período transitório, o Brasil pecou na elaboração de estratégias que lhe permitiriam alcançar uma maior qualidade no desenvolvimento, optando por já lançar sua nova Lei de Propriedade Industrial, de n. 9.279, de 1996, em estrita consonância àquele acordo. Assim, conforme acentua Grangeiro ${ }^{39}$, "na elaboração da Lei de Patentes o Brasil deixou de

36 SILVA, Tatianna Mello Pereira da. Acordo TRIPS: one-sizefits-all?. In: Revista de Direito Internacional, v. 10, n. 1, Brasília, 2013, p. 69. Disponível em: < file:///C:/Users/Note\%20Michele/ Downloads/1987-11447-1-PB.pdf> Acesso em: 03 jul. 2017.

37 VARELLA, Marcelo Dias. Propriedade Intelectual e Desenvolvimento, São Paulo: Lex, 2005, p. 03

38 Ibidem, p. 13

39 GRANGEIRO, Alexandre; TEIXEIRA, Paulo Roberto. Repercussões do Acordo de Propriedade Intelectual no acesso a medicamentos. In: Propriedade Intelectual: tensões entre o capital e a sociedade. VILLARES, Fábio (Org.) São Paulo: Paz e Terra, 2007, p. 130 
incorporar diversas salvaguardas, assim como, na atualidade, utiliza os mecanismos de proteção previstos na sua própria lei de forma tímida."

Consistente em um dos ramos da Propriedade Intelectual, a Propriedade Industrial pode ser compreendida como um promissor instrumento de desenvolvimento, merecendo particular atenção o instituto das patentes. Atentando para a construção teórica realizada por Correa $^{40}$, tem-se que o sistema de patentes carrega consigo a intenção original de recompensar o espírito inventivo, incentivando, com isso, o progresso técnico.

$\mathrm{O}$ instituto das patentes persegue o ideal de impulsionar o progresso técnico-industrial, fomentando a realização e a divulgação de invenções. Estas, por sua vez, de acordo com a conceituação trazida por Assa$\mathrm{fim}^{41}$, consistem em regras para a ação humana e são o resultado de um processo criador, pressupondo a apresentação de um problema e a determinação dos meios para solucioná-lo.

Conceituando o mesmo instituto, Macedo e Pinheiro ${ }^{42}$ esclarecem que a patente consiste em uma das propriedades industriais e envolve conhecimentos não triviais de base técnica, científica e legal. Em sua origem, surgiu como uma política de cunho desenvolvimentista para incentivar os artesãos a criar novos processos e mercadorias e a produzi-las localmente, sendo o inventor a peça principal da lógica da concessão do monopólio em troca do benefício da revelação do conhecimento.

A partir dessa perspectiva, a patente pode ser encarada como um incentivo concedido pelo Estado para que novas invenções sejam criadas. Ocorre que, na prática vivenciada pelo mundo globalizado, não se consegue mais vislumbrar tal incentivo. Considerando que os titulares das patentes passam a ser as grandes corporações, o instituto acaba sendo encarado restritivamente como uma ferramenta de monopólio, mediante a pre-

40 CORREA, Carlos M. Aperfeiçoando a Eficiência Econômica e a Equidade pela Criação de Leis de Propriedade Intelectual. In: Propriedade Intelectual e Desenvolvimento. Marcelo Dias Varella (Org.). São Paulo: Lex, 2005, p. 51-52.

41 ASSAFIM, João Marcelo de Lima. A Transferência de Tecnologia no Brasil (aspectos conceituais e concorrenciais da Propriedade Industrial). Rio de Janeiro: Lumen Juris, 2013, p. 19.

42 MACEDO, Maria Fernanda Gonçalves; PINHEIRO, Eloan dos Santos. O impacto das Patentes Farmacêuticas em Países em Desenvolvimento e as Perspectivas para o Brasil. In: Propriedade Intelectual e Desenvolvimento. Marcelo Dias Varella (Org.). São Paulo: Lex, 2005, p. 282. dominância das regras de mercado sobre o interesse social desenvolvimentista.

Sob esse mesmo enfoque, discorre Assafim ${ }^{43}$ que as patentes de invenções têm a função primordial de servir de instrumento de tecnologia. Não obstante, nos países subdesenvolvidos ou em desenvolvimento, existe uma espécie de desconfiança frente às patentes de invenções como portadoras de tecnologias. Com frequência, imagina-se que as mesmas somente servem às empresas dos países industrializados para que explorem, em regime de monopólio, nos países menos desenvolvidos as invenções, sem que seja transmitida a tecnologia correspondente.O titular de uma patente recebe, por um período de 20 anos, o direito exclusivo de

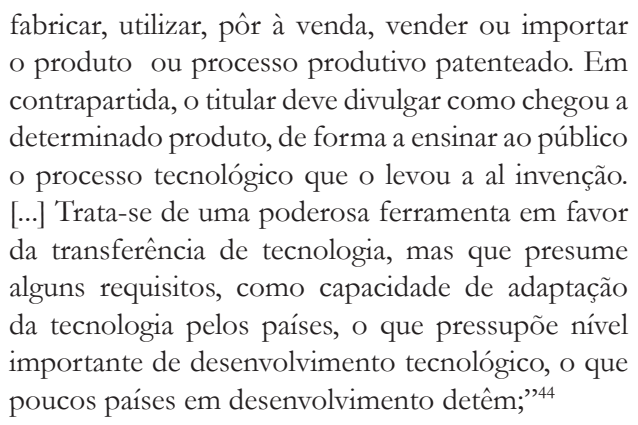

A grande maioria dos teóricos são defensores da criação de um sistema de patentes para os Estados, pois sem ele não haveria desenvolvimento científico e tecnológico, principalmente na era da globalização, onde o aspecto comercial está realçado em todos os âmbitos do cotidiano social." 45

Pertinente se faz a reflexão sobre a tradição brasileira quanto ao uso de patentes, que já é de longa data, o que se depreende até mesmo pela ativa participação do país nos tratados e acordos internacionais pertinentes ao tema. Sobre esse aspecto, explica Gontijo ${ }^{46}$ que a lei de patentes, de 28 de agosto de 1830 , previa a concessão de patentes apenas a nacionais, sendo que aos estrangeiros interessados em explorar localmente suas invenções

43 ASSAFIM, João Marcelo de Lima. Op Cit., p. 20.

44 VARELLA, Marcelo Dias. Políticas Públicas para Propriedade Intelectual no Brasil. In: Propriedade Intelectual e Desenvolvimento. Marcelo Dias Varella (Org.). São Paulo: Lex, 2005, p. 188.

45 BENETTI, Daniela Vanila Nakalski. Proteção Às Patentes de Medicamentos e Comércio Internacional. In: Propriedade Intelectual e Desenvolvimento. Welber Barral e Luiz Otávio Pimentel (Orgs.). Florianópolis: Fundação Boiteux, 2006, p. 346.

46 GONTIJO, Cícero. As transformações do sistema de Patentes, da Convenção de Paris ao Acordo Trips. A posição brasileira. Fundação Heinrich Böll. 2005. Disponível em: < http:/ / paje.fe.usp. br/ mbarbosa/dpi/gontijo1.pdf > Acesso em: 20 mar. 2017, p. 17. 
era concedido um subsídio (muito diferente do monopólio). Além disso, a lei previa a caducidade, nos casos em que houvesse a ausência de exploração local após dois anos da concessão.

Atualmente, o sistema patentário brasileiro segue os ditames previstos na Lei $\mathrm{n}^{\circ}$. 9.610/98, que regula todas as modalidades de Propriedade Industrial. A patente é concedida pelo governo, por intermédio do Instituto Nacional de Propriedade Industrial (INPI), oportunidade em que são atribuídos ao solicitante o direito de propriedade sobre o seu objeto e o direito de impedir terceiros de usá-la sem seu consentimento, prerrogativas que se estendem pelo prazo de vinte anos contados a partir da solicitação do privilégio. ${ }^{47}$

Conforme esclarece Marinho ${ }^{48}$, o INPI se trata de uma autarquia federal autossuficiente, que independe de repasses do governo, sendo responsável por executar as normas que regulam a propriedade industrial, tendo em vista sua função social, econômica, jurídica e técnica, o que retrata a importância da sua atuação na condução do sistema brasileiro de patentes. Contudo, entende-se que a sua estrutura não se mostra compatível com a importância que o sistema representa, o que se depreende em razão da demora na análise dos pedidos, diante da falta de profissionais destinados a essa função.As dificuldades enfrentadas pelo INPI, sobretudo no tocante à mão-de-obra, repercutem negativamente no sistema patentário. De acordo com o entendimento de Benetti ${ }^{49}$,é a partir da proteção do conhecimento científico e tecnológico e da sua transformação em inovação que se alcança o desenvolvimento socioeconômico do país. Em razão disso, a Propriedade Intelectual e, sobretudo, a Propriedade Industrial, é vista como um elemento essencial para o desenvolvimento interno.

Por outro lado, defendendo uma posição não tão otimista, Suguieda ${ }^{50}$ alerta que quando se está a tratar

47 MACEDO, Maria Fernanda Gonçalves; PINHEIRO, Eloan dos Santos. O impacto das Patentes Farmacêuticas em Países em Desenvolvimento e as Perspectivas para o Brasil. In: Propriedade Intelectual e Desenvolvimento. Marcelo Dias Varella (Org.). São Paulo: Lex, 2005, p. 282.

48 MARINHO, Maria Edelvacy Pinto Marinho. Política de Patentes em Biotecnologia: posicionamento Brasileiro. In: Propriedade Intelectual e Desenvolvimento. Marcelo Dias Varella (Org.). São Paulo: Lex, 2005, p. 317.

49 BENETTI, Daniela Vanila Nakalski. Op. Cit., p. 43.

50 SuguIEDA, Márcio Heidi. O Tênue Equilíbrio da Propriedade Intelectual no Brasil. In: Propriedade Intelectual e Transferência de Tecnologia. Patrícia Aurélia Del Nero (Coord.). Belo Horizonte: Fórum, 2011, p. 65. de países em desenvolvimento, é interessante desmistificar argumentações que almejam incutir a ideia de que a proteção em si da propriedade intelectual é fator que promove a inovação tecnológica ou a atração de investimentos. Para o autor, trata-se de um fator a ser considerado, mas não pode ser visto em sentido absoluto.De acordo com a perspectiva trazida por Varella $a^{51}$, a gestão da concessão de patentes possui uma face técnica, que é representada pelo cumprimento dos acordos internacionais, atendendo ao mínimo previsto pelo TRIPS e pelos outros tratados em vigor no Brasil, e outra política, que está fundamentada no cumprimento da função social da propriedade, representada pela escolha dos formuladores de políticas públicas sobre quais setores estimular por meio da concessão de patentes e quais setores estimular por meio da não-concessão de direitos de propriedade intelectual.Se a conjuntura dessas duas faces da concessão de patentes se der de maneira equilibrada, entende-se pela possibilidade de se pensar o sistema patentário enquanto propulsor do desenvolvimento nacional.

\section{Como bem observa Correa ${ }^{52}$, \\ o reconhecimento dos direitos de propriedade intelectual fundamenta-se essencialmente na suposição de que, na falta de incentivos, os investimentos pra criar novo conhecimento ficarão abaixo do nível ótimo. Os criadores de políticas enfrentam o difícil dilema de sacrificar o bem- estar de hoje em vista de benefícios futuros. As abordagens desse dilema precisam considerar o contexto em que ocorre o processo de inovação e difusão de conhecimento.}

Nesse sentido, fundamental se apresenta a promoção de incentivo por parte do Estado, para que novas pesquisas sejam desenvolvidas e revertam em desenvolvimento econômico e social para a comunidade local, ao invés de limitar-se ao cumprimento das normas de caráter internacional, tornando-se mero fornecedor de matéria prima para que as grandes multinacionais adquiram maior monopólio global.Conforme propõe Remiche ${ }^{53}$, a construção de um sistema das patentes equi-

51 VARELLA, Marcelo Dias. Políticas Públicas para Propriedade Intelectual no Brasil. In: Propriedade Intelectual e Desenvolvimento. Marcelo Dias Varella (Org.). São Paulo: Lex, 2005, p. 189

52 CORREA, Carlos M. Aperfeiçoando a Eficiência Econômica e a Equidade pela Criação de Leis de Propriedade Intelectual. In: Propriedade Intelectual e Desenvolvimento. Marcelo Dias Varella (Org.). São Paulo: Lex, 2005, p. 72.

53 REMICHE, Bernard. Revolução Tecnológica, Globalização e Direito das Patentes. In: Propriedade Intelectual e Desenvolvimento. Marcelo Dias Varella (Org.). São Paulo: Lex, 2005, p. 128. 
librando os diferentes interesses, internacionais e locais, deverá ser uma solução política, ou seja, resultar de uma vontade coletiva e, claro, preparada com estudos interdisciplinares.

Dentro dessa mesma perspectiva, já alertou Barbo$\mathrm{sa}^{54}$ para o fato de que a Carta Magna previu uma finalidade específica para a propriedade industrial, qual seja, o desenvolvimento tecnológico, social e econômico do País, não da humanidade, não dos países em geral. Nesse sentido, imprescindível se mostra a adoção de uma gestão dos direitos de propriedade industrial mais voltada para as demandas econômicas e sociais do país.

\section{Considerações finais}

O artigo proporcionou uma reflexão sobre a maneira como o Sistema Internacional de proteção da Propriedade Intelectual foi sendo construído e as diferentes formas como impactou nos países desenvolvidos e naqueles que ainda se encontravam em estágio de desenvolvimento. Além disso, evidenciou a forte disputa de interesses que sempre esteve por trás do firmamento dos acordos mais importantes envolvendo a matéria.

A posição de superioridade e de poder exercida pelos países desenvolvidos no cenário internacional foi o suficiente para inserir o ramo da Propriedade Intelectual no sistema de comércio internacional. Como resultado disso, o Acordo TRIPS surgiu com um enfoque totalmente diferenciado do trazido pela sua antecessora Convenção de Paris. Enquanto esta última detinha um tom conciliatório, respeitando os interesses e a autonomia dos países, o outro, ainda que se dizendo respeitar a autonomia dos Estados partes, acabou por amarrá-los a um sistema rígido de proteção.Como visto, a proteção internacional da Propriedade Intelectual trouxe sensíveis impactos para a formação dos sistemas patentários, refletindo, por sua vez, no desenvolvimento de alguns países. No caso do Brasil, ao abrir mão do prazo de transição possibilitado pelo próprio TRIPS, incorporando suas diretrizes à sua legislação interna de maneira quase que automática, acabou abrindo mão também de desenvolver-se localmente.Diante das reflexões reali-

54 BARBOSA, Denis Borges. Trips e a Experiência Brasileira. In: Propriedade Intelectual e Desenvolvimento. Marcelo Dias Varella (Org.). São Paulo: Lex, 2005. p. 144 zadas, foi possível observar que o sistema de patentes possui um viés técnico e outro político, sendo que a observância às normas internacionais, embora indispensáveis, compõem apenas o primeiro viés, restando ainda o aspecto político. Este, diz respeito à autonomia que o país detém, sendo capaz de traçar estratégias que incentivem, no plano interno, a realização de novas pesquisas e a criação de novas tecnologias, o que, por sua vez, poderá contribuir de maneira mais efetiva para o desenvolvimento nacional.

Logo, como consideração conclusiva, tem-se que o sistema internacional de proteção da Propriedade Intelectual impactou de maneira direta no desenvolvimento interno, que, se não fosse por uma decisão política adotada pelo Brasil ao aderir ao Acordo TRIPS sem a devida maturidade, poderia hoje ter índices muito mais satisfativos, seja do ponto de vista econômico, social e até mesmo tecnológico.

\section{ReferênCIAs}

ALBUQUERQUE, Eduardo da Motta e. Propriedade Intelectual e estratégias para o desenvolvimento. In: Propriedade Intelectual: tensões entre o capital e a sociedade. VILLARES, Fábio (Org.) São Paulo: Paz e Terra, 2007. Pp. 140-175

ASSAFIM, João Marcelo de Lima. A Transferência de Tecnologia no Brasil (aspectos conceituais e concorrenciais da Propriedade Industrial). Rio de Janeiro: Lumen Juris, 2013.

BARBOSA, Denis Borges. Trips e a Experiência Brasileira. In: Propriedade Intelectual e Desenvolvimento. Marcelo Dias Varella (Org.). São Paulo: Lex, 2005. Pp. 129-170.

BASSO, Maristela. O Direito Internacional da Propriedade Intelectual. Porto Alegre: Livraria do Advogado, 2000.

BENETTI, Daniela Vanila Nakalski. Proteção Às Patentes de Medicamentos e Comércio Internacional. In:

Propriedade Intelectual e Desenvolvimento. Welber Barral e Luiz Otávio Pimentel (Orgs.). Florianópolis: Fundação Boiteux, 2006. Pp. 300-329

BOFF, Salete Oro. Proteção Jurídica à ciência e à tecnologia de setores emergentes. In: Propriedade Intelectual, Gestão da Inovação e Desenvolvimento: 
patentes, marcas, softwares, cultivares, indicações geográficas, núcleos de inovação tecnológica. Salete Oro Boff; Luiz Otávio Pimentel (orgs.) Passo Fundo: IMED, 2009.

BRASIL. Presidência da República. Decreto n ${ }^{\circ}$ 635, de 21 de agosto de 1992. Promulga a Convenção de Paris para a Proteção da Propriedade Industrial, revista em Estocolmo a 14 de julho de 1967. Disponível em: < http://www.planalto.gov.br/ccivil_03/decreto/1990-1994/D0635.htm> Acesso em: 20 mar. 2017.

BRASIL. Presidência da República. Decreto nº 1.355, de 30 de dezembro de 1994. Disponível em: < http:// www.planalto.gov.br/ccivil_03/decreto/antigos/ d1355.htm> Acesso em: 20 mai. 2017.

CORREAA, Daniel Rocha. Contratos de Transferência de Tecnologia. Belo Horizonte: Movimento editorial da Faculdade de Direito da UFMG, 2005.

CORREA, Carlos M. Aperfeiçoando a Eficiência Econômica e a Equidade pela Criação de Leis de Propriedade Intelectual. In: Propriedade Intelectual e Desenvolvimento. Marcelo Dias Varella (Org.). São Paulo: Lex, 2005. Pp. 35-74.

FONTES, André R. C. Perfis de Transferência de Tecnologia. In: Propriedade Intelectual e Transferência de Tecnologia. Patrícia Aurélia Del Nero (Org.) Belo Horizonte: Fórum, 2011.

GONTIJO, Cícero. As transformações do sistema de Patentes, da Convenção de Paris ao Acordo Trips. A posição brasileira. Fundação Heinrich Böll. 2005. Disponível em: < http://paje.fe.usp.br/ mbarbosa/dpi/ gontijo1.pdf > Acesso em: 20 mar. 2017.

GRANGEIRO, Alexandre; TEIXEIRA, Paulo Roberto. Repercussões do Acordo de Propriedade Intelectual no acesso a medicamentos. In: Propriedade Intelectual: tensões entre o capital e a sociedade. VILLARES, Fábio (Org.) São Paulo: Paz e Terra, 2007, pp. 115-139

MACEDO, Maria Fernanda Gonçalves; PINHEIRO, Eloan dos Santos. O impacto das Patentes Farmacêuticas em Países em Desenvolvimento e as Perspectivas para o Brasil. In: Propriedade Intelectual e Desenvolvimento. Marcelo Dias Varella (Org.). São Paulo: Lex, 2005. Pp. 277-304

MARINHO, Maria Edelvacy Pinto Marinho. Política de Patentes em Biotecnologia: posicionamento Brasilei- ro. In: Propriedade Intelectual e Desenvolvimento. Marcelo Dias Varella (Org.). São Paulo: Lex, 2005. Pp. 305-326.

MERCER, Henrique da Silva. Patente de Medicamentos conforme o TRIPS: O caso da Gripe Aviária. In: Propriedade Intelectual e Desenvolvimento. Welber Barral e Luiz Otávio Pimentel (Orgs.). Florianópolis: Fundação Boiteux, 2006.

REMICHE, Bernard. Revolução Tecnológica, Globalização e Direito das Patentes. In: Propriedade Intelectual e Desenvolvimento. Marcelo Dias Varella (Org.). São Paulo: Lex, 2005. Pp. 75-128

ROLAND, Manoela Carneiro. O debate sobre o Desenvolvimento sob a perspectiva estratégica da Propriedade Intelectual e da sua regulamentação internacional. In: Patrícia Aurélia Del Nero (Coord.) Propriedade Intelectual e Transferência de Tecnologia. Belo Horizonte: Fórum, 2011.

SACHS, Jeffrey. O divisor global de Inovação. In: Propriedade Intelectual e Desenvolvimento. Marcelo Dias Varella (Org.). São Paulo: Lex, 2005. Pp. 21-34

SILVA, Tatianna Mello Pereira da. Acordo TRIPS: onesize-fits-all? In: Revista de Direito Internacional. v. 10, n. 1, Brasília, 2013, p. 68. Disponível em: < file:///C:/ Users/Note\%20Michele/Downloads/1987-11447-1PB.pdf> Acesso em: 03 jul. 2017.

SUGUIEDA, Márcio Heidi. O Tênue Equilíbrio da Propriedade Intelectual no Brasil. In: Propriedade Intelectual e Transferência de Tecnologia. Patrícia Aurélia Del Nero (Coord.). Belo Horizonte: Fórum, 2011.

VARELLA, Marcelo Dias; PLATIAU, Ana Flávia Barros; SCHLEICHER, Rafael T. Desenvolvimento Tecnológico, Pesquisa Pública e Propriedade Intelectual: Análise da Miríade de Normas Internacionais. In: Propriedade Intelectual e Desenvolvimento. Marcelo Dias Varella (Org.). São Paulo: Lex, 2005. Pp. 327-360

Propriedade Intelectual e Desenvolvimento. São Paulo: Lex, 2005.

Políticas Públicas para Propriedade Intelectual no Brasil. In: Propriedade Intelectual e Desenvolvimento. Marcelo Dias Varella (Org.). São Paulo: Lex, 2005. Pp. 171-232. 
Para publicar na Revista de Direito Internacional, acesse o endereço eletrônico www.rdi.uniceub.br ou www.brazilianjournal.org.

Observe as normas de publicação, para facilitar e agilizar o trabalho de edição. 